\title{
Modulating Effects of the Menstrual Cycle on Cardiorespiratory Responses to Exercise under Acute Hypobaric Hypoxia
}

\author{
Kazuko TAKASE, Takeshi NISHIYASU, and Katsumi ASANO \\ Laboratory of Exercise Physiology, Institute of Health and Sport Sciences, \\ University of Tsukuba, Tsukuba, 305-8574 Japan
}

\begin{abstract}
The purpose of this study was to examine the hypothesis that the menstrual cycleinduced modulation of the cardiorespiratory response to exercise might be altered by acute exposure to altitude. During both the luteal and follicular phases, 9 moderately trained female subjects with normal menstrual cycles performed incremental exercise to maximal effort on a cycle ergometer at sea level (SL) and under hypobaric hypoxia $(\mathrm{HH})$ at the equivalent of $3,000 \mathrm{~m}$ altitude. Both at rest and during exercise, minute ventilation $(\dot{V} \mathrm{E})$ and oxygen uptake $\left(\dot{V}_{2}\right)$ did not differ between the luteal and follicular phases (ei-
\end{abstract}

ther at SL or $\mathrm{HH})$. However, the ratio of $\dot{V} \mathrm{E}$ to $\dot{V} \mathrm{O}_{2}\left(\dot{V} \mathrm{E} / \dot{V} \mathrm{O}_{2}\right)$, both at rest and during peak exercise, was greater in the luteal phase than in the follicular phase under $\mathrm{HH}$ conditions. Furthermore, the partial pressure of end-tidal carbon dioxide $\left(P \mathrm{ET}_{\mathrm{CO}_{2}}\right)$ during exercise was lower in the luteal phase than in the follicular phase in $\mathrm{HH}$. These results suggest that the menstrual cycle-induced modulation of the ventilatory response to exercise may be altered under acute hypobaric-hypoxic conditions. [Japanese Journal of Physiology, 52, 553-560, 2002]

Key words: cycle exercise, altitude training, ventilatory response, luteal phase.

\begin{abstract}
Anecdotal evidence, recently supported by scientific evidence, suggests that altitude training may offer advantages over sea-level (SL) training [1-5]. As a consequence, many elite athletes, female as well as male, now train at high altitude in an effort to enhance their SL performance. It is known that the menstrual cycle modulates thermoregulatory and cardiorespiratory responses, both at rest and during exercise, but it is not yet clear how this modulation is altered by moving to a higher altitude $(\leq 3,000 \mathrm{~m})$, either acutely or chronically.

In the luteal phase of the menstrual cycle, increased body-core temperature and high levels of progesterone are found. Progesterone has been shown to stimulate minute ventilation $(\dot{V} \mathrm{E})[6,7]$ and to be associated with a decrease in alveolar carbon dioxide tension in the luteal phase [8-10]. Moreover, hypoxic ventilatory response (HVR) at rest is increased in the luteal
\end{abstract}

phase, although amenorrheic women show no such significant modulation in HVR [10, 11]. Further, eumenorrheic women show a greater hypercapnic ventilatory response (HCVR) at rest in the luteal phase than in the follicular phase $[10,12-14]$. Thus, the increased ventilatory response in the luteal phase is thought to be due to progesterone lowering the threshold of the medullary respiratory center and increasing its excitability [15].

Given the stimulatory effects of progesterone on resting $\dot{V} \mathrm{E}[7,16], \dot{V} \mathrm{E}$ during exercise would also be expected to be higher in the luteal phase than in the follicular phase. While a number of studies have indeed demonstrated an increase in $\dot{V}$ E during maximal or submaximal exercise in the luteal phase $[10,13,14$, $17,18]$, other studies have found no differences [19-23]. As a result of the increased body-core temperature in the luteal phase, oxygen uptake $\left(\dot{V}_{2}\right)$ dur- 
ing exercise, like $\dot{V} \mathrm{E}$, would be expected to be higher than in the follicular phase. However, most studies have reported no significant difference in maximal or submaximal exercise $\dot{V} \mathrm{O}_{2}$ between these two phases $[10,17,20-27]$, although one study did find a difference [18]. It should be clear from the above that the presence of a modulating effect of the menstrual cycle on respiratory and metabolic responses to exercise at sea level, and still less its nature, has not yet been demonstrated.

During exposure to acute hypobaric hypoxia $(\mathrm{HH})$, ventilation is enhanced both at rest and during dynamic exercise as compensation for the effects of the decrease in the inspiratory $\mathrm{O}_{2}$ content [28]. Conceivably, these effects of $\mathrm{HH}$ might alter the menstrual cycle-induced modulation of the cardiorespiratory response to exercise. However, it is not known whether this is indeed the case. In fact, very few studies have dealt with this issue, although Beidleman et al. [19] found that $\dot{V} \mathrm{E}$ during dynamic exercise performed either at sea level or during acute exposure to a simulated $4,300 \mathrm{~m}$ altitude was no greater in the luteal phase than in the follicular phase, and that neither maximal nor submaximal exercise performance was affected by the phase of the menstrual cycle at either of these altitude levels. In general, the effects of $\mathrm{HH}$ on ventilatory response to exercise are known to depend on the altitude, and most athletic training is now conducted at below $3,000 \mathrm{~m}$. For female athletes who usually reside at sea level, information about such modulations would help both in the planning of their training program and in the assessment of their performance when they train at high altitude. Although the significant effects of altitude training per se may derive from longtime acclimation to altitude, an obvious first step in elucidating the effects of the menstrual cycle at altitude seemed to be to study the effects of acute altitude exposure. This being so, when we set out to examine the possible menstrual cycle-induced modulation of the cardiorespiratory response to exercise, and the hypothesis that it might be different between sea level and altitude, we studied acute altitude exposure and chose a simulation level of $3,000 \mathrm{~m}$.

\section{METHODS}

Volunteer subjects. Ten moderately trained female athletes volunteered for this study. One of them completed the study, but was eliminated from any further analysis because of inadequate menstrualcycle documentation; so we are actually reporting nine subjects. All subjects were nonsmokers, had no history of cardiopulmonary disease, and were taking no medication. Their mean age, height, initial body weight, and \%body fat were $20.2 \pm 1.7$ years, $161.2 \pm$ $3.6 \mathrm{~cm}, 54.4 \pm 4.3 \mathrm{~kg}$, and $25.3 \pm 3.2 \%$, respectively. Each of them had a menstrual cycle of $25-32 \mathrm{~d}$, and none had taken oral contraceptives or hormone therapy for at least 1 year before entering the study. None were pregnant, and none had ever been pregnant. Hemoglobin values were normal $(12.4 \pm 0.7 \mathrm{~g} / \mathrm{dl})$.

All volunteers were lifelong residents at low altitude, and none had had any exposure to altitudes $>1,000 \mathrm{~m}$ for at least 1 year before the study. They had all engaged in tennis $5-7 \mathrm{~d} /$ week for $2-5 \mathrm{~h} / \mathrm{d}$ for at least 12 months prior to the study. This study was approved by the Human Subjects Committee of the University of Tsukuba, and each subject gave written informed consent.

Menstrual-cycle documentation. Supportive evidence for normal ovulatory cycles was initially obtained by use of a menstrual cycle-history questionnaire. At the time of enrollment, all subjects were considered to be eumenorrheic (11-14 cycles/year) on the basis of their previous 1 year menstrual-cycle histories. Confirmation of menstrual status during the study was obtained through analysis of daily basal body-temperature charts, and serum estradiol and progesterone levels. A serum progesterone less than $5 \mathrm{ng} / \mathrm{ml}$ was accepted as confirmation of the luteal phase [29].

Study protocol. The study used a balanced experimental design in which each volunteer's ovarian hormones, ventilatory parameters, and exercise performance were evaluated at SL and during $\mathrm{HH}$ in both the follicular (approximately 6-12 d after the onset of the menses) and the luteal (5-10d after the day of ovulation) phases of the menstrual cycle. The four test conditions were: (1) sea level, follicular (SL/F); (2) sea level, luteal (SL/L); (3) acute altitude, follicular $(\mathrm{HH} / \mathrm{F})$; and (4) acute altitude, luteal (HH/L). In each session, peak $\mathrm{O}_{2}$ uptake $\left(\dot{V}_{2}\right.$ peak $)$ and ventilatory threshold $\left(T_{\text {vent }}\right)$ were measured [30]. All exercise tests were performed at the same time on each day. To minimize training and/or order effects, the four test conditions (SL/F, SL/L, HH/F, and HH/L) were randomized. A given subject took part in only one session on a given day, and in two sessions ( $\mathrm{SL}$ and $\mathrm{HH}$ ) in a given menstrual phase with an interval of $1 \mathrm{~d}$.

Environmental conditions. Each exercise test was performed in a hypobaric chamber maintained at a temperature of $20 \pm 1^{\circ} \mathrm{C}$, a relative humidity of $60 \pm$ $10 \%$, and at ambient $\mathrm{O}_{2}$ and $\mathrm{CO}_{2}$ concentrations of 20.9 and $0.03 \%$, respectively. At 1 week before the first test, each volunteer entered the chamber in order to familiarize herself with the experimental condi- 
tions: at this time, the chamber was decompressed to the barometric equivalent of $3,000 \mathrm{~m}$ for $20 \mathrm{~min}$. For the exercise test under the $\mathrm{HH}$ condition, the chamber was gradually decompressed to the barometric equivalent of $3,000 \mathrm{~m}(526 \mathrm{mmHg})$. The time required for decompression was $20 \mathrm{~min}$. The exercise test, which was started at $10 \mathrm{~min}$ after decompression had been completed, took approximately $15 \mathrm{~min}$. Before the exercise test at SL, to keep the subjects unaware of the environmental conditions, the chamber was gradually decompressed to the barometric equivalent of $1,000 \mathrm{~m}$ $(674 \mathrm{mmHg})$ over a period of $10 \mathrm{~min}$, and then gradually returned to SL over a period of $10 \mathrm{~min}$. For each test, three test-conductors and one subject entered the chamber.

Ovarian-hormone analysis. Ovarian-hormone levels were measured to enable us to document the phase of the menstrual cycle. A resting blood sample was obtained from a large antecubital vein before each exercise test for measurement of estradiol and progesterone levels. A serum progesterone value $>5 \mathrm{ng} / \mathrm{ml}$ was accepted as confirmation of the mid-luteal phase [29]. The serum concentrations of estradiol and progesterone were determined in duplicate by means of a solid-phase ${ }^{125}$ I radioimmunoassay (Diagnostic Products Corporation, Los Angeles, CA, USA). The limit of detection was $8 \mathrm{pg} / \mathrm{ml}$ for serum estradiol and $0.02 \mathrm{ng} / \mathrm{ml}$ for serum progesterone. The intraassay coefficients of variation were less than $10 \%$.

Peak-exercise test. Before each peak-exercise test, the subjects were asked to abstain from alcohol and caffeine for at least $24 \mathrm{~h}$, and to refrain from exercising on the day of the test. Exercise such as high-intensity tennis might lead to exhaustion, and was not permitted in the last $2 \mathrm{~d}$ before testing. The subject came to the laboratory more than $1 \mathrm{~h}$ after awakening following overnight fasting. We then took anthropometric measurements, and a blood sample was drawn at rest. Before each exercise test, the subject was weighed (wearing only T-shirt and shorts) to the nearest $0.1 \mathrm{~kg}$, and her body composition (\% body fat) was measured using a bioimpedance system (HBF-300; Omron, Tokyo, Japan). After a $10 \mathrm{~min}$ rest, a resting gas sample was obtained via a sampling mask after the subject had been sitting on a chair for $3 \mathrm{~min}$. Respiratory gases in each breath were measured continuously during the peak-exercise test using a respiromonitor (RM300i; Minato, Osaka, Japan) and a medical gas analyzer (MGA-1100; Perkins Elmer, Milwaukee, USA), which were calibrated using certified gases and a volume standard. $\dot{V} \mathrm{E}$ (BTPS) was measured using a hot-wire flowmeter, and $\dot{V}_{\mathrm{O}_{2}}$ (STPD) and carbon dioxide output $\left(\dot{V} \mathrm{CO}_{2}, \mathrm{STPD}\right)$ were measured for alternate minutes throughout the period of exercise with the aid of a computerized system. $\dot{V} \mathrm{O}_{2}$ peak was determined by means of a progressive work-exercise test protocol (using $90 \mathrm{kpm} / \mathrm{min}$ (60 rpm) increments up to maximal effort). During exercise, heart rate (HR) was recorded using a HR monitor (PE300; Polar, Kempele, Norway). Maximal effort was indicated by the exercise continuing to exhaustion, and the time to exhaustion was measured. $\dot{V} \mathrm{O}_{2}$ peak was taken as the plateau value achieved following an increase in workload. End-tidal $\mathrm{O}_{2}$ and $\mathrm{CO}_{2}$ concentrations $\left(F \mathrm{ET}_{\mathrm{O}_{2}}, F \mathrm{ET}_{\mathrm{CO}_{2}}\right)$ and respiratory exchange ratio (RER) were monitored at the mouth with the aid of a mass spectrometer. Exercise data were tabulated for each of the gas collection periods. Gas exchange parameters $\left(\dot{V} \mathrm{O}_{2}, \dot{V} \mathrm{E}\right.$, and $\left.\dot{V} \mathrm{CO}_{2}\right)$ were used as follows to estimate $T_{\text {vent }}$ [30]. Break-points in the $\dot{V} \mathrm{CO}_{2}-\dot{V} \mathrm{O}_{2}$ and $\dot{V} \mathrm{E}-\dot{V} \mathrm{O}_{2}$ curves, representing a switch to non-linear increases in $\dot{V} \mathrm{CO}_{2}$ and $\dot{V} \mathrm{E}$ relative to $\dot{V} \mathrm{O}_{2}$, were detected visually and used to locate the $T_{\text {vent }}$. The $T_{\text {vent }}$ values obtained from these two curves were not significantly different $(p>0.05)$, and so they were averaged for further analysis. The ventilatory equivalents for $\mathrm{O}_{2}$ and $\mathrm{CO}_{2}$ were expressed as $\dot{V} \mathrm{E} / \dot{V} \mathrm{O}_{2}$ and $\dot{V} \mathrm{E} / \dot{V} \mathrm{CO}_{2}$, respectively. The $\mathrm{O}_{2}$ pulse was expressed as $\dot{V} \mathrm{O}_{2} / \mathrm{HR}$. Values for the rating of perceived exertion (RPE) were obtained at rest and during exercise using the whole-body Borg scale [31]. Partial pressures of end-tidal $\mathrm{O}_{2}$ and $\mathrm{CO}_{2}\left(P \mathrm{ET}_{\mathrm{O}_{2}}, P \mathrm{ET}_{\mathrm{CO}_{2}}\right)$ were calculated from $F \mathrm{ET}_{\mathrm{O}_{2}}$ and $F \mathrm{ET}_{\mathrm{CO}_{2}}$, respectively, and the barometric pressure measured on the day of the experimental session.

Statistical analysis. All data are presented as means \pm SD. Differences between testing conditions (altitude) as well as differences between follicular and luteal phases were assessed using a multiple-comparison one-way analysis of variance (ANOVA) for repeated measures, with significance set at $p<0.05$. Scheffe's post hoc comparisons were used to identify significant differences among means.

\section{RESULTS}

\section{Estradiol and progesterone levels}

Among subjects in the follicular phase, resting estradiol levels were within the range 6 to $192 \mathrm{pg} / \mathrm{ml}$, and progesterone levels were 0.5 to $1.8 \mathrm{ng} / \mathrm{ml}$. Among subjects in the luteal phase, the corresponding values were 74 to $236 \mathrm{pg} / \mathrm{ml}$ and 5 to $16 \mathrm{ng} / \mathrm{ml}$. Mean resting estradiol and progesterone levels (Table 1) were within previously reported normal ranges for eumenorrheic women [29]. 
Table 1. Serum levels of ovarian hormones under the four test conditions.

\begin{tabular}{lcrrr}
\hline & \multicolumn{4}{c}{ Condition phase } \\
\cline { 2 - 5 } & SL/F & SL/L & $H H / F$ & $H H / L$ \\
\hline Progesterone $(\mathrm{ng} / \mathrm{ml})$ & $1.22 \pm 0.42$ & $6.28 \pm 2.82^{\mathrm{a}}$ & $1.17 \pm 0.41$ & $8.91 \pm 4.15^{\mathrm{b}}$ \\
Estradiol $(\mathrm{pg} / \mathrm{ml})$ & $48.4 \pm 30.4$ & $176.0 \pm 57.8^{\mathrm{a}}$ & $65.5 \pm 57.7$ & $126.8 \pm 46.7^{\mathrm{b}}$ \\
\hline
\end{tabular}

SL/F: sea level, follicular; SL/L: sea level, luteal; HH/F: hypobaric hypoxia, follicular; HH/L: hypobaric hypoxia, luteal. Values are means $\pm S D ; n=9$. Significant differences $(p<0.05):{ }^{a}$ vs. $S L / F ; b$ vs. HH/F.

\section{Rest}

The cardiopulmonary data collected at rest are presented in Table 2 and Fig. 1. There were no significant differences between menstrual-cycle phases or between altitude levels in RPE, RER, tidal volume $(V \mathrm{~T})$, respiratory rate, $\dot{V} \mathrm{E}, \dot{V} \mathrm{O}_{2}, \dot{V} \mathrm{CO}_{2}, \dot{V} \mathrm{E} / \dot{V} \mathrm{CO}_{2}, P \mathrm{ET}_{\mathrm{CO}_{2}}$, or $\dot{V} \mathrm{O}_{2} / \mathrm{HR}$. Although there was no altitude-difference in $\dot{V} \mathrm{E} / \dot{V} \mathrm{O}_{2}$, it was higher by $19 \%$ in $\mathrm{SL} / \mathrm{L}$ than in $\mathrm{SL} / \mathrm{F}$, and higher by $17 \%$ in $\mathrm{HH} / \mathrm{L}$ than in $\mathrm{HH} / \mathrm{F}$ (Fig. 1). HR was significantly higher at $\mathrm{HH}$ than at SL in the follicular phase, but not in the luteal phase.

\section{Exercise}

Cardiopulmonary parameters collected at $T_{\text {vent }}$ and at peak-exercise are presented in Table 2 and Fig. 1.

\section{Submaximal data (at $\boldsymbol{T}_{\text {vent }}$ )}

At $T_{\text {vent }}$ : (1) $\dot{V} \mathrm{O}_{2}$ was not affected by menstrualcycle phase (it was $\sim 20 \%$ lower at $\mathrm{HH}$ than at $\mathrm{SL}$ in each phase); (2) $\dot{V}$ E was affected by neither menstrualcycle phase nor altitude; (3) $\dot{V} \mathrm{E} / \dot{V} \mathrm{O}_{2}$ was unaffected by menstrual-cycle phase at both altitudes nor by altitude in either phase (Fig. 1a); (4) at altitude, $\dot{V} \mathrm{E} / \dot{V} \mathrm{CO}_{2}$ was greater in the luteal phase; (5) $P \mathrm{ET}_{\mathrm{CO}_{2}}$ was lower by $\sim 13 \%$ at $\mathrm{HH}$ than at SL (in both phases), and showed a menstrual-cycle phase difference only during $\mathrm{HH}$ (Fig. 1b), its value being $8 \%$ lower in $\mathrm{HH} / \mathrm{L}$ than in $\mathrm{HH} / \mathrm{F}(p<0.05) ;(6) \dot{V} \mathrm{O}_{2} / \mathrm{HR}$ was not affected by menstual-cycle phase, $\mathrm{HH}$ decreased it only in the follicular phase; and (7) there were no phase or altitude differences in RER, $V \mathrm{~T}$, respiratory rate, $\dot{V} \mathrm{CO}_{2}$, or HR.

\section{Peak data (at exhaustion)}

Neither menstrual-cycle phase nor altitude affected the exercise time to exhaustion (Table 1). At peak: (1) there was no phase difference in $\dot{V} \mathrm{O}_{2}$ at either altitude, but in each phase it was lower by $\sim 18 \%$ at $\mathrm{HH}$ than at SL; (2) $\dot{V}$ E was not affected by menstrual-cycle phase or altitude; (3) during $\mathrm{HH}, \dot{V} \mathrm{E} / \dot{V} \mathrm{O}_{2}$ was $\sim 35 \%$ greater than at SL in each phase, and showed a phase difference only during $\mathrm{HH}$, the value being $27 \%$ higher in
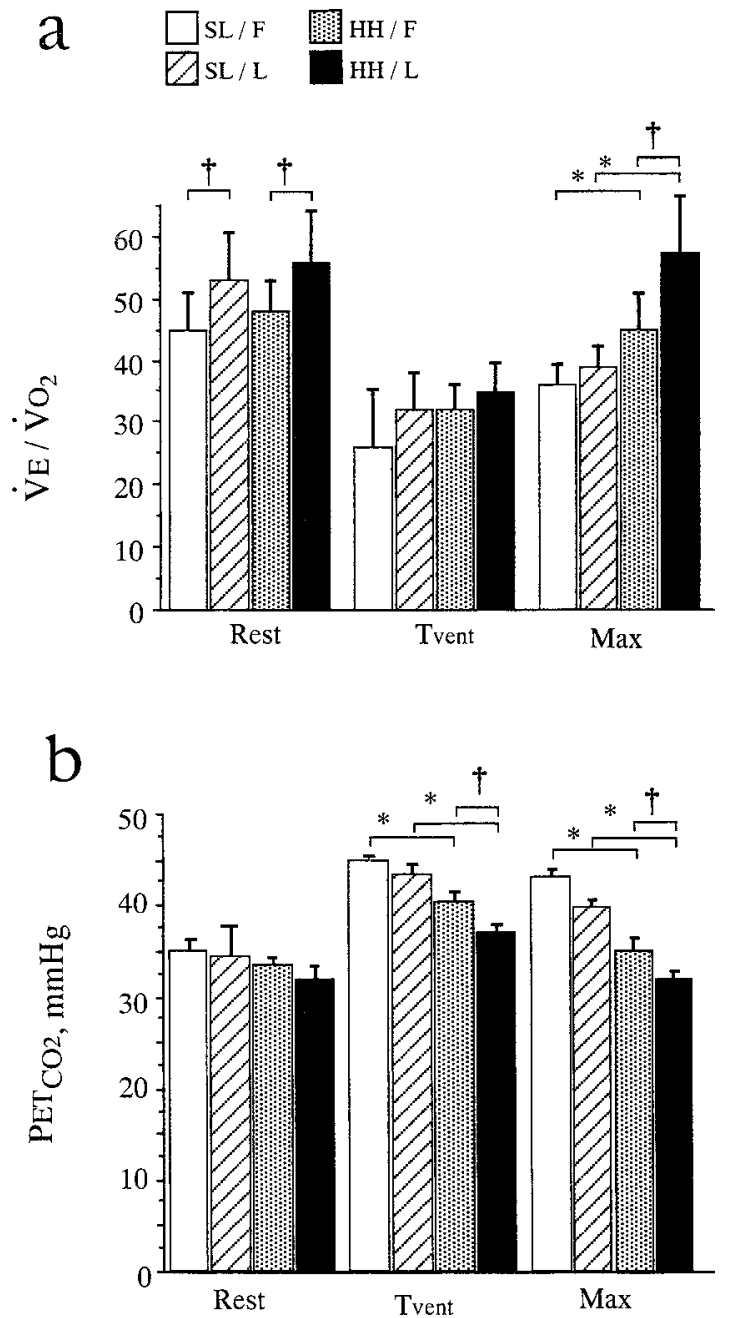

Fig. 1. Comparisons in respect of (a) ventilatory equivalent for oxygen $\left(\dot{V} \mathrm{E} / \dot{V} \mathrm{O}_{2}\right)$ and (b) the partial pressure of end-tidal carbon dioxide $\left(P E T_{\mathrm{CO}_{2}}\right)$ at sea level $(\mathrm{SL})$ and $3,000 \mathrm{~m}(\mathrm{HH})$ in the follicular $(\mathrm{F})$ and luteal $(\mathrm{L})$ phases. Significant differences $(p<0.05)$ : * between SL and $\mathrm{HH}$ in same phase of the cycle; ${ }^{\dagger}$, between $\mathrm{F}$ and $\mathrm{L}$ at the same altitude equivalent.

$\mathrm{HH} / \mathrm{L}$ than in HH/F (Fig. 1a); (4) HR was unaffected by phase or altitude; (5) $\dot{V} \mathrm{O}_{2} / \mathrm{HR}$ was $\sim 22.3 \%$ lower at $\mathrm{HH}$ than at $\mathrm{SL}$; (6) $P \mathrm{ET}_{\mathrm{CO}_{2}}$ was lower at $\mathrm{HH}$ than at SL in both phases, and it showed a phase difference only during $\mathrm{HH}$, the $\mathrm{HH} / \mathrm{L}$ value being $8 \%$ lower than 
Menstrual Cycle and Respiration in Hypoxia

Table 2. Physiological parameters at rest and during an incremental maximal exercise test.

\begin{tabular}{|c|c|c|c|c|}
\hline & SL/F & $\mathrm{SL} / \mathrm{L}$ & $\mathrm{HH} / \mathrm{F}$ & $\mathrm{HH} / \mathrm{L}$ \\
\hline \multicolumn{5}{|c|}{ Exercise time (min) } \\
\hline exhaustion & $12.2 \pm 1.4$ & $12.6 \pm 1.6$ & $11.0 \pm 1.4$ & $11.3 \pm 1.5$ \\
\hline \multicolumn{5}{|l|}{ RPE } \\
\hline rest & $6.6 \pm 0.9$ & $6.6 \pm 0.9$ & $6.5 \pm 0.8$ & $6.3 \pm 0.5$ \\
\hline Tvent & $14.1 \pm 1.4$ & $14.3 \pm 1.0$ & $11.9 \pm 1.8^{*}$ & $12.7 \pm 1.9$ \\
\hline \multicolumn{5}{|l|}{ RER } \\
\hline rest & $0.85 \pm 0.07$ & $0.86 \pm 0.04$ & $0.89 \pm 0.05$ & $0.86 \pm 0.02$ \\
\hline Tvent & $0.93 \pm 0.06$ & $0.98 \pm 0.11$ & $0.97 \pm 0.06$ & $1.00 \pm 0.09$ \\
\hline exhaustion & $1.23 \pm 0.04$ & $1.26 \pm 0.13$ & $1.37 \pm 0.08^{*}$ & $1.31 \pm 0.04$ \\
\hline \multicolumn{5}{|l|}{$\operatorname{VT}(1)$} \\
\hline rest & $0.51 \pm 0.08$ & $0.51 \pm 0.14$ & $0.45 \pm 0.07$ & $0.51 \pm 0.09$ \\
\hline Tvent & $1.29 \pm 0.21$ & $1.37 \pm 0.26$ & $1.21 \pm 0.25$ & $1.29 \pm 0.26$ \\
\hline exhaustion & $1.71 \pm 0.15$ & $1.77 \pm 0.18$ & $1.73 \pm 0.24$ & $1.79 \pm 0.23$ \\
\hline \multicolumn{5}{|c|}{ Resp. R. (fr $/ \mathbf{m i n})$} \\
\hline rest & $16.9 \pm 5.1$ & $20.5 \pm 3.6$ & $19.2 \pm 4.5$ & $21.2 \pm 4.2$ \\
\hline Tvent & $28.5 \pm 5.8$ & $30.6 \pm 6.9$ & $28.9 \pm 5.2$ & $31.4 \pm 7.3$ \\
\hline exhaustion & $46.7 \pm 8.4$ & $50.3 \pm 6.3$ & $51.0 \pm 10.2$ & $54.3 \pm 4.7$ \\
\hline \multicolumn{5}{|l|}{$\dot{\mathrm{VE}}(1 / \mathrm{min})$} \\
\hline rest & $8.8 \pm 1.6$ & $10.3 \pm 2.3$ & $9.1 \pm 1.6$ & $10.6 \pm 1.8$ \\
\hline Tvent & $38.0 \pm 10.1$ & $42.6 \pm 13.1$ & $36.5 \pm 8.8$ & $40.6 \pm 12.1$ \\
\hline exhaustion & $77.9 \pm 12.2$ & $87.0 \pm 16.4$ & $81.2 \pm 18.3$ & $92.8 \pm 17.0$ \\
\hline \multicolumn{5}{|l|}{$\dot{\mathrm{VO}}_{2}(\mathrm{ml} / \mathrm{min})$} \\
\hline rest & $182 \pm 20$ & $181 \pm 40$ & $186 \pm 26$ & $206 \pm 33$ \\
\hline Tvent & $1370 \pm 273$ & $1358 \pm 390$ & $1091 \pm 217^{*}$ & $1069 \pm 335^{*}$ \\
\hline exhaustion & $2187 \pm 334$ & $2150 \pm 296$ & $1744 \pm 206^{*}$ & $1727 \pm 375^{*}$ \\
\hline \multicolumn{5}{|c|}{$\dot{\mathrm{VO}}_{2} /$ body weight $(\mathrm{ml} / \mathrm{kg} / \mathrm{min})$} \\
\hline rest & $3.3 \pm 0.3$ & $3.3 \pm 0.6$ & $3.4 \pm 0.4$ & $3.6 \pm 0.3$ \\
\hline Tvent & $24.0 \pm 3.5$ & $24.8 \pm 5.0$ & $19.3 \pm 2.2^{*}$ & $19.4 \pm 2.8 *$ \\
\hline exhaustion & $38.7 \pm 3.4$ & $39.6 \pm 3.0$ & $32.5 \pm 1.8 *$ & $31.5 \pm 4.6^{*}$ \\
\hline \multicolumn{5}{|l|}{$\dot{\mathrm{VCO}}_{2}(\mathrm{l} / \mathrm{min})$} \\
\hline rest & $157 \pm 20$ & $179 \pm 42$ & $160 \pm 24$ & $189 \pm 33$ \\
\hline Tvent & $1243 \pm 330$ & $1381 \pm 484$ & $1071 \pm 243$ & $1110 \pm 329$ \\
\hline exhaustion & $2583 \pm 298$ & $2810 \pm 549$ & $2348 \pm 549$ & $2409 \pm 522$ \\
\hline \multicolumn{5}{|l|}{$\dot{\mathrm{VE}} / \dot{\mathrm{VCO}}_{2}$} \\
\hline rest & $52.9 \pm 6.9$ & $58.1 \pm 8.7$ & $54.4 \pm 5.5$ & $61.0 \pm 6.9$ \\
\hline Tvent & $30.7 \pm 3.0$ & $31.4 \pm 3.8$ & $33.9 \pm 2.7$ & $36.7 \pm 3.6^{*}$ \\
\hline exhaustion & $29.8 \pm 2.7$ & $31.9 \pm 2.2$ & $34.2 \pm 4.6^{*}$ & $41.2 \pm 5.3 * \dagger$ \\
\hline \multicolumn{5}{|l|}{ HR (bpm) } \\
\hline rest & $65 \pm 6$ & $67 \pm 6$ & $72 \pm 6^{*}$ & $72 \pm 10$ \\
\hline Tvent & $135 \pm 16$ & $137 \pm 18$ & $136 \pm 9$ & $142 \pm 14$ \\
\hline exhaustion & $178 \pm 9$ & $180 \pm 9$ & $175 \pm 7$ & $176 \pm 7$ \\
\hline \multicolumn{5}{|c|}{$\dot{\mathrm{V}}_{2} / \mathrm{HR}(\mathrm{ml} / \mathrm{beat})$} \\
\hline rest & $3.3 \pm 0.3$ & $3.3 \pm 0.6$ & $3.4 \pm 0.4$ & $3.6 \pm 0.3$ \\
\hline Tvent & $24.0 \pm 3.5$ & $24.8 \pm 5.0$ & $19.3 \pm 2.2^{*}$ & $19.4 \pm 2.8 *$ \\
\hline exhaustion & $38.7 \pm 3.4$ & $39.6 \pm 3.0$ & $32.5 \pm 1.8^{*}$ & $31.5 \pm 4.6^{*}$ \\
\hline \multicolumn{5}{|l|}{$\mathrm{PET}_{\mathrm{O} 2}(\mathrm{mmHg})$} \\
\hline rest & $111 \pm 4$ & $114 \pm 4$ & $62 \pm 3^{*}$ & $65 \pm 4^{*} \dagger$ \\
\hline Tvent & $98 \pm 5$ & $101 \pm 4$ & $57 \pm 3^{*}$ & $57 \pm 2 *$ \\
\hline exhaustion & $113 \pm 3$ & $115 \pm 3$ & $71 \pm 3^{*}$ & $73 \pm 1 *$ \\
\hline
\end{tabular}

RPE, rate of perceived exertion; RER, respiratory exchange ratio; $V T$, tidal volume; Resp. R., respiratory rate; $\dot{V} E$, minute ventilation; $\dot{V} \mathrm{O}_{2}$, oxygen uptake; $\dot{V} \mathrm{CO}_{2}$, carbon dioxide output; $\dot{V} \mathrm{E} / \dot{V} \mathrm{CO}_{2}$, ventilatory equivalent for $\mathrm{CO}_{2} ; \mathrm{HR}$, heart rate; $\dot{V} \mathrm{O}_{2} / \mathrm{HR}, \mathrm{O}_{2}$ pulse; $P \mathrm{ET}_{\mathrm{O}_{2}}$, partial pressure of end-tidal $\mathrm{O}_{2}$. Other abbreviations: see Table 1. Values are means \pm SD. Significant differences $(p<0.05)$ : * between SL (sea level) and HH (hypobaric hypoxia) in same phase of the cycle; ${ }^{\dagger}$ between follicular and luteal phases at same altitude. 
the $\mathrm{HH} / \mathrm{F}$ value (Fig. $1 \mathrm{~b}$ ).

\section{DISCUSSION}

In this study, we measured the cardiorespiratory responses to cycle exercise up to maximal levels during the follicular and luteal phases of the menstrual cycle, both at sea level and under moderate $\mathrm{HH}$ conditions (equivalent of $3,000 \mathrm{~m}$ ). Our principal finding was that, although at rest or during exercise neither $\dot{V} \mathrm{E}$ or $\dot{V} \mathrm{O}_{2}$ in the luteal phase was significantly different between $\mathrm{SL}$ and $\mathrm{HH}$, the $\dot{V} \mathrm{E} / \dot{V} \mathrm{O}_{2}$ values obtained at rest or during peak exercise at $\mathrm{HH}$ were significantly greater in the luteal than in the follicular phase. In addition, we found that the $P \mathrm{ET}_{\mathrm{CO}_{2}}$ values obtained during exercise (at $T_{\text {vent }}$ or peak) in either luteal or follicular phase were lower at $\mathrm{HH}$ than at SL. These findings seem to suggest that modulation of the ventilatory response to exercise occurs due to the menstrual cycle, and is altered when the subject moves to moderate $\mathrm{HH}$ conditions.

Under moderate $\mathrm{HH}$ conditions (simulation of $3,000 \mathrm{~m}$ ) in both menstrual phases, $\dot{V} \mathrm{O}_{2}$ peak was decreased by $\sim 18 \%$ compared to the value at SL. Recently, Beidleman et al. [19] reported that at a simulated $4,300 \mathrm{~m}$ altitude, $\dot{V} \mathrm{O}_{2}$ peak was $\sim 27 \%$ lower than $\mathrm{SL}$ in both phases (luteal and follicular). The above data are consistent with those in previous reports showing that the reduction in $\dot{V} \mathrm{O}_{2}$ peak is dependent on the altitude $[1,2,32]$. Most studies have reported that differences in $\dot{V} \mathrm{O}_{2}$ during maximal or submaximal exercise were not significant between the luteal and follicular phases at SL [10, 17, 20-27], but one study has found such a difference [18]. For instance, it has been reported that: (1) cycle-ergometer performance at an intensity of $60-70 \% \dot{V} \mathrm{O}_{2}$ peak or less is associated with no significant difference in $\dot{V} \mathrm{O}_{2}$ between the luteal and follicular phases [25]; (2) performance of high-intensity $\left(90 \% \dot{V}_{\mathrm{O}_{2} \text { peak }}\right)$ exercise is enhanced in the luteal phase as opposed to the follicular phase [26]; but (3) there is no difference between these phases when the performance of high-intensity treadmill exercise $(90 \%$ $\dot{V}^{\mathrm{O}_{2} \text { peak }}$ ) is examined [23]. As far as altitude is concerned, both Beidleman et al. [19] (at 4,300 m) and our report (at $3,000 \mathrm{~m}$ ) found that $\dot{V} \mathrm{O}_{2}$ peak was not affected by the phase of the menstrual cycle. Since $\dot{V} \mathrm{O}_{2 \text { peak }}$ is generally taken to be an indicator of aerobic work capacity, the above results would seem to suggest that, in trained women, the phase of the menstrual cycle has little or no influence over aerobic work capacity at moderate altitude (e.g., 3,000 m, 4,300 m).

At SL, $\dot{V} \mathrm{E}$ tended to be higher in the luteal phase than in the follicular phase both at rest and during exercise, but the differences were not significant. Given the stimulatory effects of progesterone on resting $\dot{V} \mathrm{E}$ $[7,10,13,14,16,33,34]$, the $\dot{V} \mathrm{E}$ during exercise would be expected to be higher in the luteal phase than in the follicular phase. However, although the results of several studies on maximal or submaximal exercise support this supposition $[8,10,17,26]$, some studies have found no difference [19, 21-24]. In most studies, including the present one, progesterone levels and exercise parameters were measured just one time in each phase of the menstrual cycle, and it is possible that we missed the highest progesterone level in the luteal phase. In fact, a few years ago Williams and Krahenbuhl [18] showed an increased exercise $\dot{V} \mathrm{E}$ at both 55 and $80 \% \quad \dot{V}_{\mathrm{O}_{2}}$ peak in the mid-luteal phase when progesterone was at the highest level in the entire luteal phase. We cannot tell whether the progesterone levels were at their peak for the luteal phase at the time we made our measurements, but at least we can say that: (1) we detected a significant difference in progesterone level between the luteal and follicular phases, and (2) the mean values we obtained for progesterone and estradiol were within the ranges quoted in previous reports. Taking all this together leads us to postulate that, at SL, $\dot{V} \mathrm{E}$ tends to be higher in the luteal phase than in the follicular phase both at rest and during dynamic exercise, but the data may be affected by individual differences (e.g., in the time at which progesterone peaks during the luteal phase).

In the present study, $\dot{V} \mathrm{E}$ values at maximal exercise level and $T_{\text {vent }}$ were unaffected by the phase of the menstrual cycle at the $3,000 \mathrm{~m}$ altitude. Beidleman et al. [19] reported similar findings, except that their chosen altitude level was $4,300 \mathrm{~m}$. In our study, $\dot{V} \mathrm{O}_{2}$ peak was decreased by altitude, and as a consequence $\dot{V} \mathrm{E} / \dot{V} \mathrm{O}_{2}$ and $\dot{V} \mathrm{E} / \dot{V} \mathrm{CO}_{2}$ were both greater at $\mathrm{HH}$ than at SL in each menstrual phase. Beidleman et al. [19] reported increases of $\sim 35$ and $22.3 \%$ in the peak-exercise values of $\dot{V} \mathrm{E} / \dot{V} \mathrm{O}_{2}$ and $\dot{V} \mathrm{E} / \dot{V} \mathrm{CO}_{2}$, respectively, at $4,300 \mathrm{~m}$ altitude (as compared to SL). It is widely known that hypoxic stimulation increases $\dot{V} \mathrm{E}$. The increase in $\dot{V} \mathrm{E} / \dot{V} \mathrm{O}_{2}$ seen during peak exercise in our HH groups is in accord with this. Although Beidleman et al. [19] did not show menstrual-cycle phase differences in $\dot{V} \mathrm{E} / \dot{V} \mathrm{O}_{2}$ and $\dot{V} \mathrm{E} / \dot{V} \mathrm{CO}_{2}$ at peak levels of exercise, in the present study we noted that the $\dot{V} \mathrm{E} /$ $\dot{V} \mathrm{O}_{2}$ and $\dot{V} \mathrm{E} / \dot{V} \mathrm{CO}_{2}$ values recorded during peak exercise were greater in the luteal than in the follicular phase during $\mathrm{HH}$. The lower $P \mathrm{ET}_{\mathrm{CO}_{2}}$ seen in the luteal phase as compared to the follicular phase during peak exercise at $\mathrm{HH}$ indicates that a hyperventilatory response occurred during peak exercise in the luteal 
phase. Although there are methodological differences between the study by Beidleman et al. [19] and the present one [(1) subjects (active vs. regularly trained, 33 years old vs. 20 years old, respectively), (2) type of exercise test (treadmill vs. bicycle ergometer), and (3) altitude $(4,300 \mathrm{~m}$ vs. $3,000 \mathrm{~m})]$, the reasons for the discrepancies in the $\dot{V} \mathrm{E} / \dot{V} \mathrm{O}_{2}$ and $\dot{V} \mathrm{E} / \dot{V} \mathrm{CO}_{2}$ results are unclear. The very presence of a modulating effect of the menstrual cycle on the respiratory and metabolic responses to exercise at SL has previously resisted a possible demonstration [10,13,14, 17-23], and there may be large individual differences in the respiratory effects of the menstrual cycle at altitude. As far as we know, the only studies on the effects of the menstrual cycle on exercise responses at high altitude are Beidleman's [19] and the present one. We therefore feel that further studies will be needed to elucidate the explanation for the difference and to explore the possible mechanisms.

Both HVR and HCVR at rest have been reported to be increased in the luteal phase at SL $[10,11,13,14]$. Possibly, the existence of additional ventilatory stimuli at moderate altitude exaggerates the modulating effects of the menstrual cycle on the respiratory response to exercise. We suggest that at moderate altitude, even in the absence of a difference in aerobic work capacity $\left(\dot{V}_{\mathrm{O}_{2} \text { peak }}\right)$ between the luteal and follicular phases, there may be reduced ventilatory efficiency $\left(\dot{V} \mathrm{E} / \dot{V} \mathrm{O}_{2}\right)$ in the luteal phase. These results lead us to the practical suggestion that elite female athletes and their coaches should be careful in devising their practice schedule in the luteal phase to take account of the hyperventilation and reduction in ventilatory efficiency that may occur in this phase during altitude training. However, we should point out that a limitation of the present study was that it dealt with the effects of "acute" altitude exposure on modulations associated with the menstrual cycle. This should be borne in mind before applying these results to "chronic" exposure to altitude (e.g., altitude training for runners and swimmers).

In conclusion, $\dot{V} \mathrm{E}$ and $\dot{V} \mathrm{O}_{2}$ (both at rest and during exercise) showed no significant elevation associated with the luteal phase, either at SL or at moderate altitude $(3,000 \mathrm{~m})$. However, $\dot{V} \mathrm{E} / \dot{V} \mathrm{O}_{2}$ (both at rest and during peak exercise) was significantly greater in the luteal phase than in the follicular phase, but only during $\mathrm{HH}$. These results suggest that the menstrual cycle-induced modulation of the ventilatory response to exercise may be altered under acute $\mathrm{HH}$ conditions.

We would like to express our sincere thanks to the volunteer subjects. We also greatly appreciate the help of Dr.
Robert Timms (English editing and critical comments). This study was supported by Grants-in-Aid for Scientific Research from the Ministry of Education, Science, and Culture of Japan.

\section{REFERENCES}

1. Asano K, Masaoka T, Mizuno K, Kumazaki Y, Lee G, Takeda $M$, and Hayakawa $Y$ : Effects of simulated altitude training on performance and aerobic work capacity in long distance runners. Med Sci Sports Exerc 24 (Suppl): 101, 1992

2. Buskirk ER, Kollias J, and Akers RF: Maximal performance at altitude and on return from altitude in conditioned runners. J Appl Physiol 23: 259-266, 1967

3. Daniels JT and Oldridge N: The effects of alternate exposure to altitude and sea level on world-class middledistance runners. Med Sci Sports 2: 107-112, 1970

4. Pugh LG: Altitude at training. J Physiol (Lond) 192: 619-646, 1967

5. Saltin B, Grover RF, Blomqvist CG, Hartley LH, and Johnson RL Jr: Maximal oxygen uptake and cardiac output after 2 weeks at $4300 \mathrm{~m}$. J Appl Physiol 25: 400-409, 1968

6. Tok $\mathrm{G}$ and Loeschke $\mathrm{HH}$ : The effect of progesterone on the medullary respiratory chemosensitivity in the cat. Pflügers Arch 382 (Suppl): R18, 1987

7. Zwillich CW, Natarino MR, Sutton FD, and Weil JV: Effects of progesterone on chemosensitivity in normal man. J Lab Clin Med 92: 262-269, 1978

8. England SE and Fahri LE: Fluctuations in alveolar $\mathrm{CO}_{2}$ and in base excess during the menstrual cycle. Respir Physiol 26: 157-161, 1976

9. Lyons HA: Centrally acting hormones and respiration. Pharmacol Ther [B] 2: 743-751, 1976

10. Schoene RB, Robertson HT, Pierson DJ, and Peterson AP: Respiratory drives and exercise in menstrual cycles of athletic and non-athletic women. J Appl Physiol 50: 1300-1305, 1981

11. Skatrud JB, Dempsey JA, and Kaiser DG: Ventilatory response to medroxyprogesterone acetate in normal subjects: time course and mechanism. J Appl Physiol 44: 939-944, 1978

12. Bonekat HW, Dombovy ML, and Staats BA: Progesterone-induced changes in exercise performance and ventilatory response. Med Sci Sports Exerc 19: 118-123, 1987

13. Schoene RB, Pierson DJ, Robertson HT, Lakshminarayan $\mathrm{S}$, and Butler $\mathrm{J}$ : The effect of progesterone on ventilatory drives and exercise. Am Rev Respir Dis 119: 357, 1979

14. Schoene RB, Pierson DJ, Robertson HT, Lakshminarayan S, and Butler J: The effect of medroxyprogesterone acetate on respiratory drives and occlusion pressure. Bull Eur Physiopathol Respir 16: 645-653, 1980

15. Plass ED and Oberst FW: Respiration and pulmonary ventilation in normal nonpregnant, pregnant, and puerperal women. Am J Obstet Gynecol 35: 441-452, 1938

16. Bayliss DA and Millhorn DE: Central neural mechanisms of progesterone action: application to the respiratory system. J Appl Physiol 73: 393-404, 1992 


\section{K. TAKASE, T. NISHIYASU, and K. ASANO}

17. Dombovy ML, Bonekat HW, Williams TJ, and Staats BA: Exercise performance and ventilatory response in the menstrual cycle. Med Sci Sports Exerc 19: 111-117, 1987

18. Williams TJ and Krahenbuhl GS: Menstrual cycle phase and running economy. Med Sci Sports Exerc 29: 1609-1618, 1997

19. Beidleman BA, Paul BR, Stephen RM, Charles SF, Vincent AF Jr, and Sllen C: Exercise VE and physical performance at altitude are not affected by menstrual cycle phase. J Appl Physiol 86: 1519-1526, 1999

20. Bemben DA, Salm PC, and Salm AJ: Ventilatory and blood lactate responses to maximal treadmill exercise during the menstrual cycle. J Sports Med Phys Fitness 35: 257-262, 1995

21. De Souza MJ, Maguire MS, Rubin KR, and Maresh CM: Effects of menstrual phase and amenorrhea on exercise performance in runners. Med Sci Sports Exerc 22: 575-580, 1990

22. Hackney AC, Curley CS, and Nicklas BJ: Physiological responses to submaximal exercise at the mid-follicular, ovulatory, and mid-luteal phases of the menstrual cycle. Scand J Med Sci Sports 1: 94-98, 1991

23. Lebrun CM, McKenzie DC, Prior JC, and Taunton JE: Effects of menstrual cycle phase on athletic performance. Med Sci Sports Exerc 27: 437-444, 1995

24. Allsen PE, Parsons P, and Bryce GR: Effect of the menstrual cycle on maximum oxygen uptake. Physician Sports Med 5: 53-55, 1977

25. Hessemer V and Bruck K: Influence of menstrual cycle on thermoregulatory, metabolic, and heart rate responses to exercise at night. J Appl Physiol 59:
1911-1917, 1985

26. Jurkowski JE, Jones NL, Toews CJ, and Sutton JR: Effects of menstrual cycle on blood lactate, $\mathrm{O}_{2}$ delivery, and performance during exercise. J Appl Physiol 51: 1493-1499, 1981

27. Stephenson LA, Kolka MA, and Wilkerson JE: Metabolic and thermoregulatory responses to exercise during the human menstrual cycle. Med Sci Sports Exerc 14: 270-275, 1982

28. Huang SY, Alexander JK, Grover RF, Maher JT, McCullough RE, McCullough RG, Moore LG, Sampson JB, Weil JV, and Reeves JT: Hypocapnia and sustained hypoxia blunt ventilation on arrival at high altitude. J Appl Physiol 56: 602-606, 1984

29. Landgren BM, Unden AL, and Diczfalusy E: Hormonal profile of the cycle in 68 normally menstruating women. Acta Endocrinol 94: 89-98, 1980

30. Beaver WL, Wasserman K, and Whipp BJ: A new method for detecting ventilatory threshold by gas exchange. J Appl Physiol 60: 2020-2027, 1986

31. Borg G: Perceived exertion as an indication of somatic stress. Scand J Rehabil Med 2: 92-98, 1970

32. Klausen K, Robinson S, Michael ED, and Myhre LG: Effect of high altitude on maximal working capacity. J Appl Physiol 21: 1191-1194, 1966

33. Takano N, Sakai A, and lida Y: Analysis of alveolar $\mathrm{PCO}_{2}$ control during the menstrual cycle. Pflügers Arch 390: 56,1981

34. White DP, Douglas NJ, Pickett CK, Weil JV, and Zwillich CW: Sexual influence on the control of breathing. J Appl Physiol 54: 874-879, 1983 